\title{
Obituary of Richard A. Murphy
}

\author{
Avril Somlyo
}

Received: 29 September 2013/Accepted: 22 October 2013/Published online: 5 November 2013

(C) Springer Science+Business Media Dordrecht 2013

Richard A. Murphy

July 4, 1938-March 9, 2013

Professor emeritus Richard Murphy (Fig. 1), a muscle physiologist who made major contributions to our understanding of the role of crossbridge phosphorylation and the nature of crossbridge interactions with the thin filament in vertebrate smooth muscle, died March 9, 2013 after a prolonged illness.

Born in Twin Falls, Idaho, he was educated at Harvard University and received his Ph.D. in physiology at Columbia University in 1964. He did post-doctoral studies with Professor Hans Weber at the Max-Planck Institute in Heidelberg, Germany and Professor David Bohr at the University of Michigan. Dick joined the Department of Physiology at the University of Virginia in 1968, where he spent his academic career and began his influential studies on the basis of contractility in smooth muscles, which culminated in his latch-bridge hypothesis in 1981 (Dillon et al. 1981).

The initial observation which set Dick on this path of investigation was reported in his most highly cited paper with his fellows Dr. Driska et al. (1981), at a time when the role of $\mathrm{Ca}^{2+}$ activated regulatory light chain $\left(\mathrm{RLC}_{20}\right)$ phosphorylation in contraction of smooth muscle was under intense investigation. This study used a newly developed two-dimensional isoelectric focusing approach to separate and quantitate phosphorylated and non-phosphorylated $\mathrm{RLC}_{20}$ species in carotid arteries stimulated with high $\mathrm{K}^{+}$. They demonstrated that RLC20 phosphorylation increased with stimulation and preceded force

A. Somlyo $(\bowtie)$

University of Virginia, Charlottesville, VA, USA

e-mail: avs5u@virginia.edu development, in support of the current hypothesis that $\mathrm{RLC}_{20}$ phosphorylation is an important physiological control mechanism in smooth muscle. However, they observed that $\mathrm{RLC}_{20}$ phosphorylation declined from its peak value to near control levels prior to attainment of peak force leading them to conclude that additional factors were involved in the maintenance of tonic isometric force. Understanding this important physiological process at the level of the crossbridge, muscle mechanics and energetics became a major focus of his laboratory over the subsequent years.

Dick and his colleagues went on to show that dephosphorylation leads to an attached, non-cycling crossbridge they termed "the latch bridge" capable of maintaining force and acting as an internal load on the remaining phosphorylated crossbridges and accounting for the measured decrease in velocity with the onset of the tonic contraction phase (Dillon et al. 1981; Aksoy et al. 1982). They suggested that these slowly- or non-cycling latch bridges could account for the well-known characteristic of smooth muscle, a high economy of force maintenance. This work evolved into the presentation of a kinetic model that could account for the development and maintenance of the latch state during a smooth muscle contraction (Hai and Murphy 1988). He proposed that this simple model could predict much of the mechanical and energetics behavior characterizing the smooth muscle of hollow organs. The model has two crossbridge cycles, the phosphorylated crossbridge cycle and the latch bridge cycle (Fig. 2a). A novel aspect of the latch bridge is that an attached crossbridge is proposed to be a substrate for MLCK and MLCP. The model is consistent with biochemical data that crossbridge phosphorylation is obligatory for crossbridge cycling and actomyosin ATPase activity and explains the observed dependencies of force and velocity on crossbridge phosphorylation. This model was 


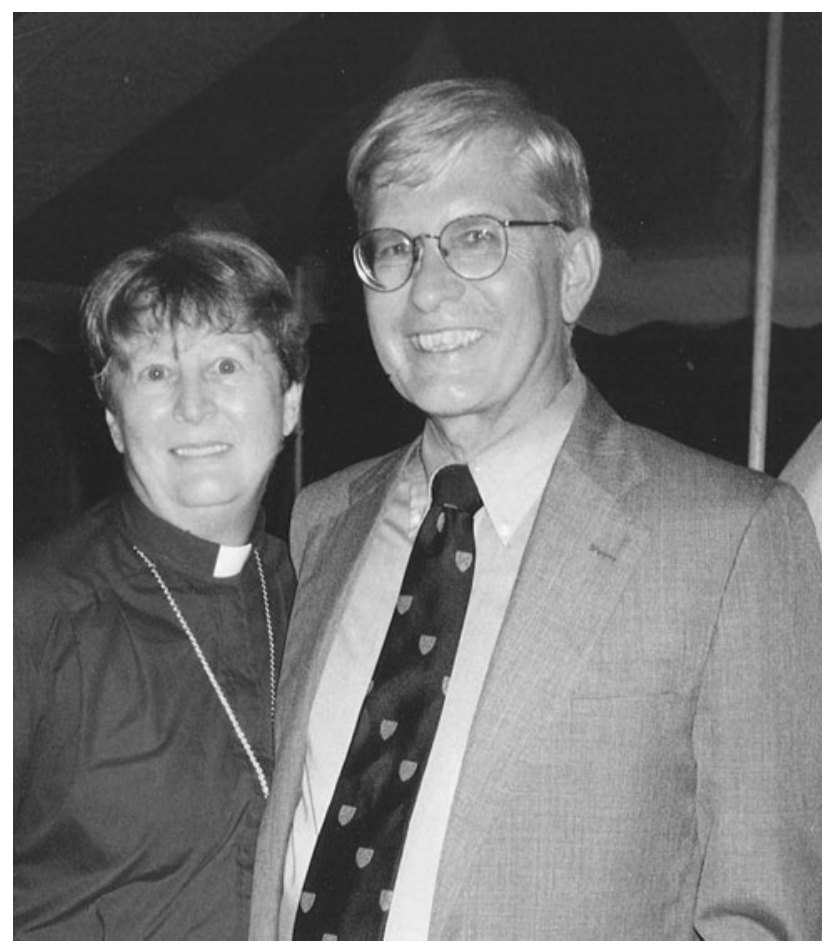

Fig. 1 Richard A. Murphy, 1938-2013 and his wife Genevieve

also used for predictions of the steady-state dependence of stress (AMp+AM), attached phosphorylated crossbridges (AMp), and of latch bridges (AM) on myosin phosphorylation (Fig. 2b; Hai and Murphy 1988). The observation in large arteries of high force at low levels of light chain phosphorylation by the Murphy group and others was a puzzle at the time. The presence of a large population of latch bridges at these low levels of light chain phosphorylation (Fig. 2b) provided an explanation. While other processes such as myosin head cooperativity, regulation of myosin phosphatase activity and thin filament regulatory mechanisms as well as strain-dependent myosin ADP off rates for example also need to be considered, nevertheless, Hai and Murphy's concept of the latch bridge and their proposed model stimulated many experiments by Dr. Murphy's group as well as other investigators and significantly moved the smooth muscle field forward.

Dick authored over 90 peer-reviewed papers, the great majority in top-tier physiology journals, and 74 chapters and review articles. These publications included significant contributions to our understanding of myosin and actin isoforms in smooth muscle. He also authored the muscle physiology sections of the 4 editions of Berne and Levy's Physiology and the 3 editions of Berne and Levy's Principles of Physiology. This in-depth understanding of muscle physiology benefited first year medical students and graduate students whom he taught for many years through lectures, his research and writings, and by example through his own high academic standards. He had an extraordinary history of continuous National Institutes of Health funding during his entire academic life. He served on innumerable academic and review committees for the University of Virginia over the course of his successful research career, and retired in 2004. His dedication to careful science and respect for the work of others made him a gifted and beloved mentor and friend to many who have gone on to make their own important contributions to science (Fig. 3).

Dr. Kris Kamm, a post doctoral fellow whose studies contributed significantly to the characterization of "latch bridges" (Aksoy et al. 1982), reminisces "The closeness felt by students, fellows and colleagues toward Dick owed in part to his soft-spoken manner that encouraged the
A

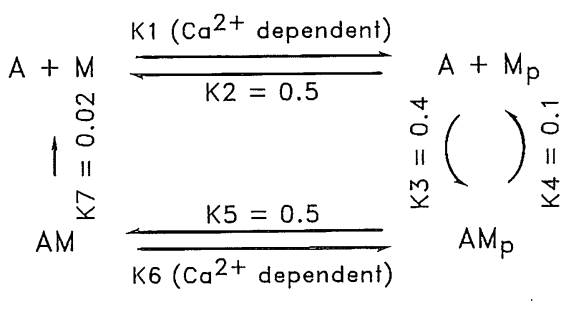

latchbridge

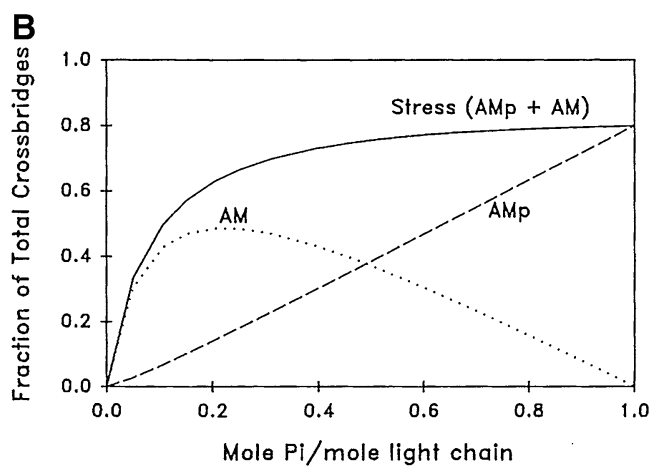

dashed line), and latch bridges (AM; dotted line) on myosin phosphorylation for the swine carotid media $37^{\circ} \mathrm{C}$. The relationships were generated by solving the system of differential equations describing the fractional content of each crossbridge species in terms of rate constants resolved from experimental data. The rate constants $K 1$ and $K 6$ representing $\mathrm{Ca}^{2+}$-dependent myosin light chain kinase activity, were changed from 0.001 to $15 \mathrm{~s}^{-1}$, which corresponded to phosphorylation levels up to $0.97 \mathrm{~mol} \mathrm{Pi} / \mathrm{mole}$ light chain. From (Hai and Murphy 1988) 


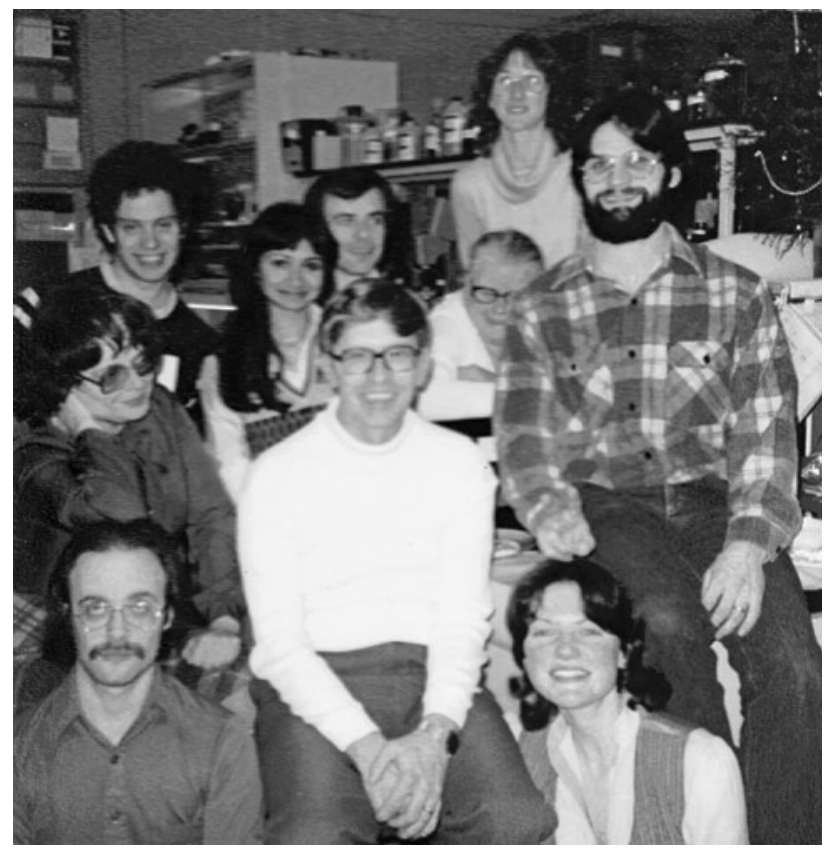

Fig. 3 Murphy laboratory circa 1981. Dick Murphy—center, clockwise from lower left Mark Aksoy, Betty Haig, Art Rovner, Mehta Chatterjee, Michael Trevethick, Mildred Smithers, Suzanne Mraz, Bill Gerthoffer, Kris Kamm

listener to lean in. He and his family often extended warm hospitality to lab members and guests at their historic country home and farmstead, Turkey Run. There, visitors encountered Dick's splendid garden in a bucolic setting that included peacocks and sheep."
Apart from his love of the land, nature, history and barbeque, Dick also loved sailing with friends and family on the Chesapeake Bay and eastern coast where he was down below as the expert chief navigator. He was an excellent marksman and was captain of the Harvard Rifle Team, which in later years proved useful in keeping the varmints off his vegetable garden.

$\mathrm{He}$ is survived by his wife Genevieve Johnson Murphy, who although having her separate career brought much joy to his life. They raised two daughters, Hayley Murphy Parrish and Wendy Murphy Wright of Charlottesville with a son-in-law Stewart A. Wright completing a close-knit family.

\section{References}

Aksoy MO, Murphy RA, Kamm KE (1982) Role of $\mathrm{Ca}^{2+}$ and myosin light chain phosphorylation in regulation of smooth muscle. Am J Physiol 242:C109-C116

Dillon PF, Aksoy MO, Driska SP, Murphy RA (1981) Myosin phosphorylation and the cross-bridge cycle in arterial smooth muscle. Science 211:495-497

Driska SP, Aksoy MO, Murphy RA (1981) Myosin light chain phosphorylation associated with contraction in arterial smooth muscle. Am J Physiol 240:C222-C233

Hai CM, Murphy RA (1988) Cross-bridge phosphorylation and regulation of latch state in smooth muscle. Am J Physiol 254:C99-C106 